Abstract P213 Table 1 Self sampling in sexual health

\begin{tabular}{|c|c|c|c|c|c|}
\hline Characteristics & Clinic only & PUP only & Mixed visits & $P$ for diff & All \\
\hline & $N=34,712$ & $N=1,691$ & $\mathrm{~N}=3,220$ & & $N=39,623$ \\
\hline $\mathrm{N}$ visits per person & $2.6(2.36)$ & $1.2(0.66)$ & $5.4(3.69)$ & $<0.001$ & $2.7(2.58)$ \\
\hline Positive $\mathrm{CT}$ at least once & $3,107(9 \%)$ & $50(3 \%)$ & $943(29 \%)$ & $<0.001$ & $4,100(10 \%)$ \\
\hline Positive GC at least once & $746(2 \%)$ & $7(0 \%)$ & $230(7 \%)$ & $<0.001$ & $983(2 \%)$ \\
\hline Positive TV* & $351(1 \%)$ & $0(0 \%)$ & $55(2 \%)$ & 0.002 & $406(1 \%)$ \\
\hline Tested for HIV/syphilis & $18,498(53 \%)$ & $27(2 \%)^{*}$ & $1,694(53 \%)$ & $<0.001$ & $20,271(51 \%)$ \\
\hline Positive HIV serology & $68(0 \%)$ & $0(0 \%)^{*}$ & $2(0 \%)$ & $0.045^{* *}$ & $70(0 \%)$ \\
\hline Positive Syphilis serology & $57(0 \%)$ & $0(0 \%)^{*}$ & $2(0 \%)$ & $0.60^{* *}$ & $59(0 \%)$ \\
\hline Known HIV positive & $27(0 \%)$ & $0(0 \%)$ & $0(\%)$ & 0.87 & $27(0 \%)$ \\
\hline \multicolumn{6}{|l|}{ Did not return for treatment } \\
\hline CT & $279(9 \%)$ & $19(38 \%)$ & $69(7 \%)$ & $<0.001$ & $367(9 \%)^{\$}$ \\
\hline GC & $73(10 \%)$ & $3(43 \%)$ & $20(9 \%)$ & $<0.001$ & $96(0 \%)^{\$}$ \\
\hline
\end{tabular}

\section{P213 SELF-SAMPLING IN SEXUAL REPRODUCTIVE HEALTH: WHO USES THIS SERVICE AND ARE WE MISSING THE OPPORTUNITY TO SCREEN FOR OTHER SEXUALLY TRANSMITTED INFECTIONS?}

Katherine Warren*, Cornelia Junghans, Dale Coley, Eleanor Draeger. Lewisham and Greenwich NHS Trust, London, UK

\subsection{6/sextrans-2016-052718.261}

Background Self-sampling kits (called Pick-up packs or PUPs in our service) have been introduced to increase STI screening in difficult to engage groups with high prevalence rates, such as male adolescents. There has been little focus on characterisation of its users.

Aim(s) To examine PUP uptake rates and describe the socio-demographic and clinical characteristics of their users compared with those attending face-to-face clinics in a large, inner city, Sexual and Reproductive Health (SRH) service in London.

Methods Retrospective study from 2012 to 2015 comparing 3 service user groups: (1) face-to-face attendances only (2) PUPs screening only (3) 'mixed attenders' using both. We compared: demographics, number of visits, STI diagnosis, treatment and HIV and syphilis testing.

Results PUP users are younger (29 yrs vs 25 yrs, p < 0.001). More men use PUP only (69\% vs 32\%). More heterosexual patients use face-to-face only (95\%) compared with mixed attenders $(89 \%)$, sexual orientation is not recorded for PUP users. No difference in ethnicity was found. Mixed attenders have the highest average number of visits and incidence of CT, GC and TV (Table 1). Incidence is lowest in the PUP only group. Nearly $40 \%$ with a CT/GC diagnosis on PUP did not return for treatment vs $10 \%$ in the other groups and only $77 \%$ had an HIV/Syphillis test. Discussion There is satisfactory uptake but uncertainty as to whether we reach the right target group. The treatment rate for STIs diagnosed using these kits is inadequate. Mixed attenders demonstrated more risk-taking behaviours.

\section{P214 HOW EASY IS IT TO DISCUSS PARTY DRUG USE IN MEN WHO HAVE SEX WITH MEN? A CLINIC SURVEY}

Nicolas Pinto-Sander*, Fionnuala Finnerty, David Atefi, Kate Yarrow, Daniel Richardson. Brighton ans Sussex University Hospitals NHS Trust, Brighton, UK
Background/introduction Party drug use is associated with poor health outcomes particularly in men who have sex with men (MSM). We have shown high and increasing rates of party drug use in MSM locally including injecting drug use (Slamming).

Aim(s)/objectives To ascertain staff confidence in discussing party drug use in MSM and to identify challenges and training needs. Methods We designed an eight-question electronic survey for health care professionals working in sexual health locally. Questions related to confidence and training required in asking MSM about party drug use.

Results 93 professionals responded (19 doctors, 26 nurses and 48 allied health care professionals including health advisers, health care assistants and pharmacists). 54/92 (59\%) of respondents felt happy with their current knowledge and 54/81 (65\%) of respondents had had specific training in party drug use. $75 / 81$ (93\%) felt they would benefit from further training. 49/91 (54\%) felt confident discussing party drug use with MSM but respondents felt less confident discussing slamming - 36/89 (41\%) felt confident, 34/89 (38\%) felt sometimes confident and $19 / 89$ (21\%) did not feel confident at all. Reported challenges included keeping up to date with new party drugs and legal highs and knowledge of the modes of administration. Small group teaching was the preferred mode of teaching.

Discussion/conclusion Even in centres where recreational drug use in MSM is high and staff receive training on drug use, it is an ever-changing landscape, and training needs to be regular and up to date preferably in a small group setting.

\section{P215 PATIENT TELEPHONE CONSULTATIONS IN A SEXUAL HEALTH SERVICE. WHAT DO THEY TELL US ABOUT SERVICE EFFICIENCY AND PATIENT NEED?}

Merle Symonds*, Liat Sarner. Barts Health NHS Trust, London, UK

\subsection{6/sextrans-2016-052718.263}

Background/introduction With an ever decreasing financial envelope, sexual health services are being tasked with developing more cost effective ways of managing patients without impacting on quality of care. Centralised patient management systems have reduced the need for face to face contact, using virtual systems, based upon Health and Social Care information Centre (HSCI) 
definitions, to manage ongoing care for patients including partner notification.

Aim(s)/objectives Analyse virtual management undertaken with patients following new attendance for episodes of STI care. To ascertain and categorise the number of virtual contacts that prevented a face to face follow up attendance.

Methods Thematic analysis was performed on a randomised sample of telephone consultations definitions between 04/15 and $01 / 16$

Results 82,994 calls were made to automated results systems. 13,373 calls were transferred from the automated system.

\begin{tabular}{ll} 
Abstract P215 Table 1 & Telephone consultations \\
\hline calls were analysed & 2719 \\
No follow up required & $969(35.6 \%)$ \\
Information, support or reassurance only & $640(23.5 \%)$ \\
Previously undiagnosed infections requiring follow up & $1054(38.8 \%)$ \\
Initiation or verification of PN & $1150(42.9 \%)$ \\
Referral to Level $1 / 2$ or other services & $68(2.5 \%)$ \\
\hline
\end{tabular}

Discussion/Conclusion The automated system manages $82 \%$ of calls without patients opting to speak with clinicians. Significant numbers of patients opted for telephone consultation upon notification of an infection, giving opportunity for initiation of PN alongside management of further testing and treatment. Approaching $1 / 4$ of consultations analysed, showed no additional testing or treatment was indicated, but advice and reassurance was the primary reason for speaking with staff. Virtual consultations can provide a high quality alternative to face to face follow-up visits.

\section{P216 COMMUNITY PHARMACY-DELIVERED CHLAMYDIA TESTING AND MANAGEMENT IN THE UK - A COMPREHENSIVE REVIEW}

${ }^{1}$ Samantha Wu*, ${ }^{1}$ Hannah Shimmin, ${ }^{1,2}$ Jo Gibbs, ${ }^{1}$ Claudia Estcourt. 'Queen Mary University of London, London, UK; ${ }^{2}$ University College London, London, UK

\subsection{6/sextrans-2016-052718.264}

Background/introduction Provision of sexual health services in community pharmacies is perceived to be a desirable strategy for increasing access to STI testing and care.

Aim(s)/objectives To comprehensively review the literature on chlamydia services in community pharmacies in the UK

Methods Eight electronic databases (Medline, AMED, BNI, CINAHL, EMBASE, HBE, HMC, PsychInfo) were searched by two researchers independently, until 4.3.16. Search terms were: (1) chlamydia, AND (2) pharmac*. Studies with qualitative or quantitative evidence on community pharmacy-based chlamydia care including screening, testing, treatment, partner notification and training were included.

Results 8 studies, published 2007-2015, met inclusion criteria. They were disparate in terms of subjects: (4 focused on pharmacy staff, 2 on clients), methodology: (2 surveys, 1 qualitative, 1 mixed methods, 1 RCT, 2 cross-sectional and 1 cost-consequence study). Focus varied: treatment 7, screening/testing 5, partner notification 4, training 1 , studies respectively. Main findings: pharmacists appear willing to offer chlamydia services if appropriately trained and supported. Barriers to offering opportunistic screening were highlighted. Two studies reported acceptability of screening/treatment but uptake by men in one study was very low (6\%). The largest study (1131 people tested positive through pharmacy) reported $47 \%$ treated in pharmacy. Preliminary feasibility and acceptability of accelerated partner therapy and expedited partner therapy were shown (2 studies).

Discussion/conclusion Despite considerable policy appetite and pharmacist support for pharmacy-delivered chlamydia care, very little robust evaluation of any element of chlamydia testing and/ or management has occurred. Well implemented studies of clinical efficacy, assessing quality of care and cost-effectiveness are warranted.

\section{P217 THE DEMAND AND PROVISION OF INTERPRETATION SERVICES IN AN INNER CITY LONDON INTEGRATED SEXUAL HEALTH CENTRE}

Esther Hunt, Patrice Grech*, Usha Kumar. King's College Hospital NHS Foundation Trust, London, UK

\subsection{6/sextrans-2016-052718.265}

Background/introduction Our centre serves a typical linguistically diverse inner city area. The General Medical Council (GMC) states we must provide our patients with information in a way they understand and, where possible, make arrangements to meet language needs. The trust has its own policy, in line with NHS England, relying exclusively on commercial medical interpretation services.

$\operatorname{Aim}(\mathbf{s}) /$ objectives To ensure we are responding to the communication and language needs of our clients in line with GMC guidance and trust policy.

Methods A retrospective case note review of patients attending between January 2014 and August 2015 coded as requiring an interpreter. A systematic sample of 100 out of 604 cases was taken.

Results 88 notes were identified as appropriately coded. Place of birth comprised 23 countries with the most common being Ecuador $(15,17 \%)$, Spain $(15,17 \%)$ and Colombia $(11,12.5 \%)$. The most common language recorded was Spanish (32, 36\%). The type of interpreter used was documented in 76 (85\%) cases with $48 \%$ of episodes using telephone Language Line. Other sources of interpretation included friend (9\%), family (3.3\%), partner (5.5\%), clinician (4.4\%) and Google Translate (11\%) with, at times, multiple sources. Average consultation time was increased by 12.7 minutes. The majority of results $(80.3 \%)$ were delivered by text in English.

Discussion/conclusion Although the trust recommends exclusive use of commercial interpretation services we are using this in only $48 \%$ of episodes. Other sources are utilised but these are not recommended by the trust. It may be that clarified departmental protocol will change practice.

\section{P218 A FULL STOP : PROVIDING A FULLY INTEGRATED SEXUAL HEALTH SERVICE FOR WOMEN ATTENDING TERMINATION SERVICES}

Joanne Hearne*, Jonathan Roberts, Amanda Davies, Jean Beard, Joanna Eley, Andrea Gibbon. Abertawe Bro Morgannwg, Swansea, UK

10.1136/sextrans-2016-052718.266

Background/introduction Traditionally Pregnancy Advice Services (PAS) stood apart from Family Planning and Genito-Urinary 